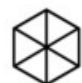 \\ LEUPHANA \\ UNIVERSITÄT LÜNEBURG
}

\section{Discourse pragmatics}

Barron, Anne; Schneider, Klaus Peter

Published in:

Pragmatics of Discourse

DOI:

10.1515/9783110214406-002

Publication date:

2014

\section{Document Version}

Publisher's PDF, also known as Version of record

Link to publication

Citation for pulished version (APA):

Barron, A., \& Schneider, K. P. (2014). Discourse pragmatics: Signposting a vast field. In A. Barron, \& K. P. Schneider (Eds.), Pragmatics of Discourse (pp. 1-33). (Handbooks of Pragmatics; Vol. III). Walter de Gruyter GmbH. https://doi.org/10.1515/9783110214406-002

\section{General rights}

Copyright and moral rights for the publications made accessible in the public portal are retained by the authors and/or other copyright owners and it is a condition of accessing publications that users recognise and abide by the legal requirements associated with these rights.

- Users may download and print one copy of any publication from the public portal for the purpose of private study or research.

- You may not further distribute the material or use it for any profit-making activity or commercial gain

- You may freely distribute the URL identifying the publication in the public portal ?

If you believe that this document breaches copyright please contact us providing details, and we will remove access to the work immediately and investigate your claim. 


\title{
1. Discourse pragmatics: signposting a vast field
}

\author{
Anne Barron and Klaus P. Schneider
}

\section{The focus of the present volume and the underlying notion of discourse}

The present handbook is one of nine volumes in the series Handbooks of Pragmatics. This series, the most comprehensive of the series of handbooks of pragmatics to date, is thematically organised and includes contributions exclusively written for this series. Each handbook is a stand-alone volume with its own specific place in the series. A certain degree of overlap between volumes is also explicitly endeavoured. This third volume belongs to the set of the first three handbooks which cover the most fundamental areas in pragmatics as it is defined for this handbook series (cf. the series editors' preface at the beginning of this volume). Volume one deals with the historical, theoretical and methodological foundations of the entire field of pragmatics (Bublitz and Norrick 2011). Following this, the next two volumes deal with two central areas, namely speech actions (the topic of volume two, Sbisà and Turner 2013), and discourse, the topic of the present third volume. Needless to say, this distinction between speech actions and discourse is purely analytical, and also reflects the beginnings of pragmatics in language studies, and specifically the impact of speech act theory on linguistics. In the conception of the series, the study of discourse, and especially of the pragmatics of discourse, is conceived not as outside the scope of pragmatics as a discipline, but rather as an integral part of it. Thus, the pragmatics of discourse and the pragmatics of utterances are two complementary levels of analysis, respectively highlighting more global and more local aspects of human communication. The latter perspective involves investigating speech acts, defined by Searle (1969: 16) as the basic unit of communication, whereas the former involves investigating, among several other phenomena, how speech acts combine into larger units such as speech act sequences (cf., e.g., FélixBrasdefer, this volume) or complete speech events. These two complementary levels of pragmatic analysis, which can be labelled the actional and the interactional levels respectively (cf. Schneider and Barron 2008: 20), have also been termed micropragmatics and macropragmatics (cf. Schneider 2003: 63-69; for a detailed discussion of these two terms, cf. Cap 2011).

The term "discourse" (and accordingly discourse analysis) can be understood in a broad or narrow sense, depending on the research tradition in which this term is used and also the underlying conceptualisation. Discourse in a narrow sense is restricted to spoken language alone, i.e. to talk. In this understanding, discourse is the opposite of text, text being viewed as a unit of written language only (corresponding 
to a folk notion or everyday understanding of "text") (cf., e.g., Titscher et al. 2000). In another, more technical use, discourse refers to the totality of a social interaction, and text, by contrast, only to its linguistic components (cf., e.g., Fairclough 2003). Often, however, the two terms, discourse and text, are used interchangeably. Further conceptualisations include discourse as a unit of language use (in the sense of Saussurean "parole", or Chomskyan "performance"; Saussure 1916/1974, Chomsky 1965), ${ }^{1}$ which contrasts with text as a unit of the language system (in the sense of "langue", or "competence"). In this view, text is at the same level of abstraction as sentence, morpheme and phoneme, while discourse would be at the same concrete and material level as utterance, morph and phone (a more detailed discussion of the specific conceptualisations of discourse in different research traditions is found in Fetzer, this volume). In the present volume, discourse is generally understood as a unit of language use. This reading is consistent with the definition of pragmatics as the study of language use in action and interaction, i.e. the definition which is adopted in this handbook series and based on the literal meaning of the term "pragmatics" (derived from the Greek word for "act" or "action"). Furthermore, the term "discourse" is employed as a cover term for "talk" and "text", i.e. for spoken as well as written discourse (cf. also, e.g., Johnstone 2008), and hence, both areas are covered in the present volume, and additionally multimodal discourse (cf. especially O'Halloran, Tan and E, this volume; also Locher, this volume; and SimonVandenbergen, this volume). Needless to say, in the contributions to this handbook, the use of the term "discourse" may differ from the general understanding outlined here, varying in accordance with the tradition of the respective approach adopted.

Discourse analysis, like the term "discourse", can be interpreted in a number of different ways and can consequently also be carried out in various fashions. It is truly an interdisciplinary field. Indeed, recently, in an effort to highlight the fact that the field is not only concerned with "analysis" but also with a broad range of theories and applications, the term "discourse studies" has been put forward to replace "discourse analysis" as the superordinate term for the field (cf., e.g., Flowerdew 2013: 1-2). At the same time, although overall discourse studies is an interdisciplinary field, it may sometimes be useful or necessary to adopt a more disciplinary perspective and concentrate on discourse linguistics or discourse psychology for particular purposes. In the present handbook, special attention is paid to linguistic aspects, given in particular the division of labour between the volumes in this handbook series, with cognitive issues dealt with in volume four (Schmid 2012), societal issues dealt with in volume five (Andersen and Aijmer 2011), and interpersonal pragmatics dealt with in volume six (Locher and Graham 2010).

Generally speaking, discourse as a complex linguistic phenomenon can be analysed from a range of different angles. The focus may be on grammatical features, which are dealt with in discourse grammar, or it may be on aspects of semantic meaning, dealt with in discourse semantics. If, however, the focus is on interactional issues, then this is the realm of discourse pragmatics. Therefore, cohesion 
and coherence, for example, are not among the phenomena with which the contributions to this handbook are primarily concerned. What they concentrate on first and foremost are communicative functions, linguistic action and participant practices in social situations.

The contributions to the present volume cover major approaches, central concepts, and representative topics in discourse pragmatics. Some chapters highlight in particular its roots and origins, and historical developments in specific areas. Other chapters examine recent trends and their potential for future research. It is to an overview of the organisation of this volume and to an outline of the individual chapters to which we turn below (cf. sections 2 and 3 ).

\section{The overall organisation of this volume}

The present handbook comprises a total of twenty-one chapters. The present introduction is followed by a second chapter of general concern which provides a detailed discussion of a range of competing, overlapping or contrasting definitions of the term "discourse" in different fields of inquiry and also of the respective conceptualisations underlying these definitions. These two introductory chapters preface the three central parts of the handbook, labelled "Approaches to discourse", "Discourse structures", and "Discourse types and domains" respectively. Parts II and III, "Discourse structures" and "Discourse types and domains", each consist of six chapters; Part I, "Approaches to discourse", comprises seven chapters.

The chapters in Part I, "Approaches to discourse", examine the role of pragmatics in major approaches to discourse studies and also discuss cross-fertilisation of concepts and approaches between these individual fields and discourse pragmatics. Specifically, these chapters cover linguistic discourse analysis, conversation analysis, systemic-functional approaches, genre analysis, critical discourse analysis, corpus-linguistic approaches, and the analysis of multimodality in discourse. The discussions show that these different approaches, each providing a specific view of language use and social practices, do not develop in isolation, but complement and influence each other.

Part II, entitled "Discourse structures", does not deal with structures in any narrow grammatical sense of this term, but with a variety of phenomena of differing complexity and status which can be characterised as functional features or elements, each structuring discourse in a specific way. In particular, these phenomena are discourse markers, stance, speech act sequences, phases in discourse, move structure and silence. This heterogeneous collection of phenomena has been studied in a range of different approaches and research traditions, with some phenomena more closely associated with a particular approach than others. Move structure, for instance, has been investigated especially in genre analysis, while discourse markers have been investigated in several approaches. 
Finally, Part III, "Discourse types and domains", highlights the involvement of discourse in the lives of individuals, in their encounters with the world and in their interactions with others. It begins with an overview of classifications and taxonomies of discourse types. This chapter demonstrates that the term "discourse type" sometimes refers to abstract subdivisions of a very general kind based, e.g., on Bühler's three or Jakobson's six language functions (Bühler 1934; Jakobson 1960). In other frameworks, however, this term may be used for much more concrete subdivisions, which are referred to as "genres" in yet other traditions. While discourse types are generally defined through functional and structural features, discourse domains, on the other hand, are typically defined through general content features and contextual features, such as discourse community. In this view, that is also adopted in the present volume, a discourse domain includes all discourse types or genres used in a given discourse community (cf. also Jucker and Taavitsainen 2012: 302, and Jucker and Taavitsainen 2010: Part VII). Four such domains are dealt with in Part III of this handbook, namely the domains of classroom, medical, legal and electronic discourse. The final chapter in Part III focuses on press releases as an example of a discourse type situated at the interface of two domains, namely media discourse and professional discourse. These chapters on individual domains also illustrate some of the approaches to discourse discussed in Part I at work.

In the design of all parts of this handbook, it was necessary to be selective. This applies in particular to Part III. Needless to say, several further domains can be distinguished, and the number of discourse types and genres is high, or even extremely high, depending on the level of specificity. Further examples of discourse domains include political discourse and workplace discourse, both of which are, however, dealt with in volume 6 of this handbook series, albeit from a different perspective (cf. Blas Arroyo 2010 on political discourse, Vine 2010 on workplace discourse). Also, further discourse features and phenomena could be added to those examined in Part II. Possible candidates could include humour or politeness. Both are examined elsewhere in this handbook series (on humour, cf. Schnurr 2010; on politeness, cf. Nevala 2010, Culpeper 2011, and Locher and Graham 2010). Finally, while the dominant approaches to discourse are covered in Part I, additional approaches could be considered, including, for instance, the ethnography of speaking or interactional linguistics, itself related to conversation analysis. For a broader picture, the reader is referred to handbooks of discourse analysis which may have made different choices, e.g. regarding discourse types and domains, and/or which may be broader in scope due either to not being focused specifically on discourse pragmatics or not being part of a handbook series with its characteristic division of labour (cf. especially Schiffrin, Tannen and Hamilton 2003; Gee and Handford 2012; and Hyland and Paltridge 2013). Also, the reader is referred to Zienkowski, Östman and Verschueren (2011), volume 8 of the ten-volume series Handbook of Pragmatics Highlights, itself based on the alphabetically organised 
encyclopaedia Handbook of Pragmatics, published and continually updated by Benjamins since 1995.

\section{The contributions}

As mentioned in section 2, the present handbook volume comprises a total of twenty-one chapters. These include the present introduction and twenty articles authored by experts from eleven countries. Each article gives an overview of the area and then provides illustrative examples of current empirical research in this area. These articles are summarised in the following.

In her article entitled "Conceptualising discourse", Anita Fetzer surveys different interpretations and uses of the term "discourse". Initially she observes that although this term occurs in a range of different contexts and with diverging meanings, it is rarely defined explicitly. Fetzer points out that the only single common denominator shared by uses of the term is an understanding of discourse as a language phenomenon above the level of the sentence. However, at the same time, such a purely quantitative definition is shown to be rather vague and generally unhelpful. After discussing some everyday notions of discourse as reflected in dictionary definitions based on qualitative rather than quantitative criteria, the author calls for a more complex and dynamic concept of discourse. Against this background, she starts her analysis of the term "discourse" as it is understood in four different research paradigms, and specifically in conversation analysis (CA), critical discourse analysis (CDA), dialogue analysis and discourse grammar. Particular emphasis is placed on paradigm-specific conceptualisations of discourse and its constitutive elements as well as on the relation between discourse and society. Fetzer demonstrates that discourse in CA is conceptualised as talk-in-interaction and as a collaborative achievement of the participants, using constructions in turns-at-talk in a strategic way (cf. Clift, this volume). CDA, on the other hand, is shown to focus on the creation of social structure, power and ideology on the micro- and macro-levels of discourse, and thus to link discourse to the broader context of social reality (cf. Bloor and Bloor, this volume). In the heterogeneous field of dialogue analysis, so the author points out, discourse is conceptualised as dialogue which can be studied in all kinds of spoken and written, everyday and institutional discourse, including literary texts. Fetzer explains that monological categories such as speaker intentions are rejected in this field, and that discourse as dialogue is defined more comprehensively in both social and cognitive terms. Finally, Fetzer notes that discourse in discourse grammar is conceptualised as a hierarchical structure, focusing in particular on the interconnectedness of its component parts. Following this discussion, the author examines two specific phenomena termed context-importation and context-invocation. She emphasises that discourse is not only embedded in context, but that it may also include context as a consti- 
tutive part. In this case, linguistic, cognitive or social context can be either imported or invocated. At the end of the chapter, Fetzer highlights the dynamic nature of discourse which in her view requires an interdisciplinary perspective for the analysis of the communicative functions and social practices in spoken, written and visual communication.

The chapter "The emergence of discourse analysis as a disciplinary field: philosophical, pedagogic and linguistic approaches" opens part one of the present volume, which deals with "Approaches to discourse". In this opening chapter, Willis J. Edmondson outlines the early development of discourse analysis as a discipline in language studies, concentrating on its roots in particular traditions in philosophy, pedagogy and linguistics, before presenting his own synthesis from these approaches and demonstrating its relevance to applications in educational contexts (cf. also the contribution by Yang and Walsh on classroom discourse in the third part of this volume). ${ }^{2}$ Initially, Edmondson defines discourse analysis broadly as "the analysis of interactive language use in social contexts". It is pointed out that its focus on use distinguishes discourse analysis from what the author terms "text grammar", while its focus on interaction, rather than action, distinguishes it from speech act analysis. "Suprasentential", as a further defining feature, is reminiscent of Widdowson's conceptualisation of discourse as the unit "above the sentence" (Widdowson 2004: 3), and also of Fetzer's starting point for her chapter on different conceptualisations of discourse (cf. above). In his own discussion of conceptual issues, Edmondson emphasises two points: first, that not only verbal, but also non-verbal aspects of discourse (including silence, cf. Ephratt's chapter in the second part of this volume) may be relevant in the analysis as well as aspects of language delivery. His second point is that not only dialogue, but also monologue is, as a rule interactive, and that the same applies, at least potentially, to written communication. This chapter is, however, focused on "two-party face-to-face spoken discourse". The author's critical survey of the emergence of discourse analysis as a discipline and specifically of the approaches contributing to this development (and their limitations) begins with language philosophy. Here Edmondson discusses not only Austin's and Searle's speech act theory (cf. Austin 1962; Searle 1969), but also the works of 18 th century philosopher Thomas Reid (cf, e.g. Stewart's edition of Reid's work, Stewart 1822), and also Bühler as a forerunner of speech act theory (cf. Bühler 1934). In his critique of speech act theory, Edmondson highlights in particular Austin's failure to convincingly deal with perlocutionary consequence and Searle's interest in universal but not language and culture specific aspects of communication as well as his exclusive focus on potentially performative acts. Following this, attention turns to Flanders' contribution to discourse analysis, Flanders (1970), who, for very practical pedagogical purposes, developed a system for observing and analysing classroom behaviour as interaction. As the prototypical sequence, he identified "teacher stimulus" - "learner response" - "teacher feedback", which is characteristic of traditional teaching styles. The overall purpose of 
empirically employing this system was to improve learning outcomes. Edmondson shows how Sinclair and Coulthard (1975), building on Flanders' work, developed a less intuitive and more comprehensive categorical system, in which discourse functions are explicitly correlated with the grammatical forms which are used to realise these functions. Sinclair and Coulthard further conceptualise discourse as a hierarchy of units (similar to Halliday's ranks, cf. Simon-Vandenbergen's contribution, this volume). Although their data material also consists of classroom discourse, Sinclair and Coulthard were not concerned with practical pedagogical issues; rather their primary concern was linguistic. They can therefore be credited with launching discourse analysis in linguistics. Addressing some points of criticism made earlier, Edmondson then presents his own model of analysis, which not only combines Sinclair and Coulthard's approach with speech act analysis, but also draws on conversation analysis (cf. Clift's contribution to this volume). When introducing his analytical apparatus, which also includes the notions of interactional strategies and discourse worlds, Edmondson stresses that in his view the central aim of discourse analysis is to specify discourse outcomes, i.e. the "results" the participants arrive at. The chapter closes with Edmondson illustrating his approach and also its practical relevance in an analysis of foreign language classroom interaction.

Rebecca Clift provides a concise overview of the fundamental tenets of conversation analysis (CA), arguably the most dominant approach to spoken discourse today. Initially, the author points out that conversation analysis is, in fact, a misnomer which has become the established term for an area more properly characterised as the study of talk-in-interaction, and whose main concern is the co-ordination of action in any kind of talk, not just in everyday conversation. After situating $\mathrm{CA}$ in the context of pragmatics and distinguishing it from related disciplines such as sociolinguistics and anthropology, the author summarises its origins and development in empirical sociology and discusses some basic methodological principles. She then demonstrates how the method of CA supports the analysis of talk-in-interaction. To illustrate this, she takes the example of turn-taking organisation, and highlights the importance of transcription and the conventions used in CA for this purpose. In the next section, Clift deals with two major aspects of the structural organisation of talk, namely the organisation of sequence and the organisation of repair. Turning first to sequence organisation, the author first highlights that the analysis of sequence organisation is the examination of coherence in interaction. Emphasising the central position of the sequence, Clift discusses the adjacency pair as the minimal coherent unit in talk and the most basic type of sequence. Furthermore, she discusses preference organisation in adjacency pairs, describing the typical features of preferred and dispreferred second turns-at-talk, before defining three types of sequences which may occur before (pre-sequences), after (post-sequences) or inside (insertion sequences) a basic adjacency pair, thus expanding this pair. In her discussion of repair organisation, the author underlines 
that this phenomenon, while aimed at the management of communication problems, must not be equated with the straightforward correction of errors. She then introduces, illustrates and discusses the four basic types of self- or other-initiated self- or other-repair and emphasises the importance of the sequence position in which repair is initiated vis-à-vis the position of the "trouble-source". In the final part of the chapter, Clift focuses on participant practices and surveys studies of such familiar actions as greetings, requests and complaints, while at the same time stressing that the findings of the specific treatment of such actions in CA, may be at odds with the intuitions of language users. She also surveys literature on practices for which no common meta-communicative term exists, such as agreeing by repeating what the interlocutor has said before. How this is accomplished and which linguistic resources are used for this purpose is exemplified in some detail. Finally, an overview is presented of (a) the linguistic resources which have been analysed in CA, (b) the languages which have been studied, and (c) the clinical areas to which a CA approach has been applied (cf. also Martin's chapter on medical discourse in the third part of the present volume).

Systemic-functional approaches to discourse are discussed by Anne-Marie Simon-Vandenbergen. Simon-Vandenbergen emphasises the origins of these approaches in Systemic-Functional Linguistics (SFL), based on Halliday's model of language (cf., e.g., Halliday 1978), and outlines the different perspectives from which discourse has been analysed in this particular tradition. At the beginning of her chapter, the author shows how Hallidayan theory is focused on language for communication in real life contexts and its functions in society. She introduces Halliday's three metafunctions - the ideational, interpersonal and textual function and demonstrates how they are related to the structure of the language system. She points out that language in this tradition is always analysed through texts and that SFL text analysis is grounded in lexicogrammatical analysis, based on the assumption that the function which a text serves in a particular context is reflected in the grammatical choices in the text. This approach is illustrated in the analysis of several text passages. The author further highlights the fact that language in SFL is seen as embedded in the context of situation and the broader context of culture, and that language is related to the former through the concept of register, while it is related to the latter through the concept of genre. These two central concepts are dealt with in separate sections. Simon-Vandenbergen starts her discussion of register by introducing the analysis of the situational context in terms of the Hallidayan notions of field, tenor and mode, i.e. the so-called register variables, which correlate with the three metafunctions. This type of analysis is then demonstrated. It is shown that the register variables and their values can be used in a classification of text types. In her discussion of genre, the author highlights different uses of this term. She refers to work on generic structures, and specifically to models which add the analysis of genre to register analysis. She then examines Appraisal Theory as a more recent development in SFL (cf. Martin and White 2005) which deals with 
interpersonal meaning in discourse beyond the lexicogrammatical level of analysis, an approach crucially concerned with attitudes and evaluations. Following this, the SFL-specific notion of discourse types is discussed. Examples are taken from scientific discourse, media discourse and historical discourse - three domains which have received considerable attention in SFL. With a focus on educational linguistics, Simon-Vandenbergen then underlines and illustrates the social commitment of discourse analysis in the SFL tradition and the contribution of research to resolving social inequalities. This aim and commitment is shared by critical discourse analysis (CDA), briefly discussed at the end of the chapter as an approach overlapping and collaborating with SFL approaches to discourse (cf. Bloor and Bloor, this volume). Finally, multimodal discourse analysis is mentioned as a recent development inspired by systemic-functional linguistics (cf. O'Halloran, Tan and $\mathrm{E}$, this volume).

Genre analysis is the next approach to discourse discussed. Christine Tardy and John Swales open this chapter with a juxtaposition of the fields of pragmatics and genre analysis. They point out that despite very different paths of historical development and a long-term association of pragmatics with small-scale spoken interactions and of genre analysis with written genres, these fields are gradually moving closer to each other, both fields interested in how individuals accomplish actions and tasks through language, both focused on communicative functions and their realisations and both now increasingly concerned with spoken and written discourse. The authors view genre analysis as a tool for discourse pragmatic research. Following this opening discussion, Tardy and Swales then proceed to sketch the theoretical and historical background of genre analysis, highlighting the focus of genre analysis on the rhetorical and social nature of genre-based communication. They point out that genres shape and are shaped by their users, that genres are intertextually linked to other genres and discourses and that genre knowledge may play a role in gatekeeping, excluding users lacking knowledge of the conventionalised norms associated with a particular genre. The article then turns to methods of genre analysis. Here, genre analysis is not presented as a single method of discourse analysis, but rather as a repertoire of methods and tools for understanding genres, their users, and their uses. These include text analysis (supported by corpus-based analysis), move structure analysis (cf. also Samraj, this volume), comparative genre analysis (comparing linguistic, national, professional or disciplinary affiliations), diachronic genre analysis, genre system analysis (focused on genres as clusters or networks), critical genre analysis and also recent methods such as multimodal/ visual genre analysis and the study of genre and identity. Each of these methods is presented in some detail and in the final section of the chapter, Tardy and Swales apply a selection of these methods to an empirical analysis of sixty texts belonging to the genre of biographical data statements (bio-statements).

Critical discourse analysis (CDA) is the approach to discourse examined by Meriel and Thomas Bloor. The focus of this chapter is on the links which exist 
between CDA and pragmatics and also on the diverse nature of research in the field of CDA. The paper begins by outlining the starting points in the development of research in CDA and by drawing attention to the commonalities and shared interests of both pragmatics and CDA and indeed this discussion of the interface of pragmatics and CDA is one which continues throughout the paper. Focus then turns to the objectives, methods (focused on those most relevant to pragmatics) and targets of critique of CDA. Following this, the chapter moves to the role of CDA in investigating the construction and maintenance of identity and then to CDA research in the area of ecology and the construction of place. The subsequent section on politeness, power and knowledge focuses on hedging. Here Brown and Levinson's $(1978,1987)$ pragmatic analysis of the universality of hedging is contrasted with a study of hedging conducted within the framework of CDA. The authors highlight the focus of the latter on the role of hedging in the construction of scientific knowledge and on the necessity of adherence to such communicative norms of showing social deference to avoid exclusion from academic publications. Focus then turns to discourse historical approaches and socio-cultural approaches to CDA, two recent approaches which deal not only with text and discourse but also to a large extent with context. The discourse historical approach dealt with goes beyond the text to relate texts to analyses of historical events and sociocultural practices. The socio-cultural approach discussed is the branch of mediated discourse analysis, an approach which is concerned with analysing, interpreting and explaining social action but which sees discourse as just one form of social action among others (including, e.g., displays of physical action, attitudes and views aired in focus groups). The role of cognitive linguistics in CDA (and indeed also pragmatics) is then discussed with particular emphasis on the contribution of Lakoff's (1987) theory of cognitive frames and also Chilton's (2004) work on frames as bundles of cultural knowledge, work which involves several pragmatic concepts. The article closes by highlighting some recent trends and areas for further analysis.

Michaela Mahlberg surveys corpus-linguistic approaches to the study of discourse. She emphasises that corpus linguistics is not merely a research methodology but also an approach which may lead to a revision of theoretical positions and existing concepts. In this context, a distinction is made between (deductive) corpus-based approaches and (inductive) corpus-driven approaches. For the purposes of this chapter, discourse analysis is defined broadly as "the analysis of language in use", and corpora, as large machine-readable collections of texts, which are seen as data sources providing naturally occurring examples of language in use for analysis. Texts, which in the author's view may be written or spoken, are considered part of social interaction. The author observes that the analysis of such texts has been largely qualitative, whereas corpus linguistics offers an additional quantitative dimension. Thus, corpora help to identify recurrent patterns, which shape people's perceptions and discourse production. Mahlberg advocates a corpus-theoretical 
approach which may serve not only as a framework for the description, but also for the interpretation and evaluation of corpus findings. This approach rests on three assumptions, namely that language is a social phenomenon, that meaning and form are linked, and that corpus-linguistic description is primarily focused on lexis. These three assumptions are then illustrated with corpus material. The author demonstrates, for instance, that even straightforward frequency information can reveal aspects of how people use language to interact in social contexts and construct social reality. Thus, she argues, corpora can be seen as sources of cultural information about societies. Patterns which emerge from concordance data are a further example. These patterns show what is repeatedly talked about and which expressions are used for these purposes. The author also highlights the significance of so-called lexical bundles (i.e. sequences of frequently co-occurring words) which may fulfill a range of discourse functions, e.g. expressing stance or organising discourse. Reference is also made to work identifying "cultural key words" such as feminism, unemployment or sustainable development, and representations of social groups which reveal attitudes and evaluations towards these groups. The author then discusses how corpora can be used or created to study phenomena across different types of discourse, including speech and writing, different institutional contexts and different thematic areas. Referring to a range of studies, she exemplifies possible sampling criteria. In the third section of this chapter, work in the related fields of corpus-assisted discourse studies and corpus-based critical discourse analysis (CDA), which has been focused predominantly on language use in politics and in the media to uncover hidden meanings and ideologies, is introduced (cf. Bloor and Bloor, this volume). The concept of semantic prosody and its role in the interpretation of corpus findings is also discussed in this context. In the final section, Mahlberg examines corpus-linguistic methods which can be employed to investigate textual units and discourse structures, focusing in particular on the cohesive functions and distributions of textual patterns in and across discourse segments.

Finally, the concluding paper in part one, "Approaches to discourse", is entitled "Multimodal Pragmatics". In this paper, Kay O'Halloran, Sabine Tan and Marissa Kwan Lin E examine the increasingly important role of visual, actional and audio resources (e.g. images, facial expressions, gesture and embodied action, proxemics, movement, sound) in contemporary communication. The authors begin by juxtaposing the goals of multi-modal studies and of pragmatics. They draw attention to the fact that both multi-modal studies and pragmatics have similar goals, both dealing with how communicative purposes are realised in particular contexts. The focus of research in pragmatics is predominantly on language; that in multimodal studies on multimodal resources and on multimodal resources in combination with language choices. A brief overview of multimodal studies then follows, touching on the use of Forceville and Urios-Aparisi's (2009) cognitive approach and Scollon's (2001) mediated and situated discourse analysis in multimodal analysis. The focus, however, is on the role of Halliday's (1978) social semiotic theory as a the- 
oretical basis for multimodal research (cf. also Simon-Vandenbergen, this volume). The next section turns to the specific topic of multimodal pragmatics. Here O'Halloran, Tan and E outline prominent studies in pragmatics which have incorporated multimodal resources in the areas of embodied and material action in talkin-interaction and in interactions with new media tools and technologies. However, the authors point out that the functions of language in relation to multimodal resources in such existing pragmatic research are not conceptualised using a common underlying theoretical framework. Taking up this deficit, O'Halloran, Tan and E put forward an approach to multimodal pragmatics which addresses this, an approach influenced by the work of Eggins and Slade (1997), Martin and Rose (2007) and Sinclair and Coulthard (1975) and also informed by Halliday's systemic functional theory (Halliday 1978; Halliday and Matthiessen 2004). This approach is illustrated via an analysis of how a formal learning task was carried out in the context of collaborative computer mediated communication using language (informal online conversation), visual resources and action. Focus is first on interpersonal meaning and the enactment of social relations in exchanging information and services. Five hierarchically organised categories of analysis are identified, namely the generic stage, sub-phase, turn, function and move. The analysis reveals that a limited set of on-task moves were realised using visual and actional resources, moves which were crucial for the completion of tasks. These included moves, such as call to attention, emotion, self-check, monitor, acceptance/agreement, concession, rejection and distraction in the task-oriented stage. The second step of the analysis then gives an overview of the number of annotations and justifications entered per number of on-task chat entries. In this way, more and less efficient groups at the annotation task are identified for each of the three schools investigated. The use of the most and least efficient group's linguistic, visual and actional resources in each of the three schools are then analysed. Findings reveal that multi-tasking, planning and dexterity help in using linguistic, visual and actional resources in the context of collaborative online communication. The authors point out, however, that these resources may also be misused. The chapter closes claiming that the study of language use demands a multimodal approach given the interdependence of language and other multimodal resources.

Part two of the present handbook deals with "Discourse structures". The first topic is that of discourse markers. Kerstin Fischer addresses this topic by first pointing out the vast array of terms (e.g. discourse markers, pragmatic markers, response tokens, discourse structuring devices, etc.) which abound in the area. The chapter then takes up the question as to whether the array of discourse markers can be grouped together or whether they are better viewed separately. Fischer considers the reasons why the object of study might comprise a single class, discussing firstly the structural characteristics of discourse markers and how they contribute to defining the class, and secondly the functional spectrum which discourse markers may fulfil. The discussion of the structural characteristics 
closes by highlighting the non-exclusivity of the formal criteria discussed; rather a prototype approach is considered appropriate, with discourse markers seen as a broad category with fuzzy boundaries. Similarly, the discussion of function concludes that discourse markers do not share a common function. On the other hand, however, discourse markers are shown to be polyfunctional. Indeed, it is this polyfunctionality and interrelatedness among functions and that which it teaches about individual discourse markers and the class of discourse markers which makes Fischer claim that the functional spectrum of discourse markers should not be torn apart, but rather assumed to be a single class. This belief in the need to leave the category of discourse markers broad so as to facilitate understanding of all possible features of discourse markers and also of the relationship between individual items is supported by an overview of the historical development of discourse markers which illustrates the variable ways in which discourse markers emerge. Having argued for an inclusive heterogeneous class, Fischer then goes a step further and proposes a set of dimensions designed to produce some order. These allow her to identify clusters of highly interrelated groups in the broad class of discourse markers.

Similar to discourse markers, stance, the topic of the second chapter in this part of the handbook, is also a term without unanimous definition, being understood and employed by different researchers in different ways. It is a term which has enjoyed an increase in popularity in recent years. Tiina Keisanen and Elise Kärkkäinen point out that the term is used variously to replace such concepts as modality, evaluation, attitude, affect and subjectivity. The authors begin the chapter by tracing back the use of the term "stance". In this context, they point out that the original use of the term related to the notion of subjectivity in language. Such early studies, particularly prevalent in the 1980s, and primarily discourse-functional and linguistic-anthropological in nature, viewed stance as subjectivity. Stance in these traditions was seen to be located in grammatical or lexical forms (e.g. modal verbs, adverbials, adjectives, nouns). They viewed stance as the representation of the attitudes and beliefs of a single speaker with regard to a particular event or state of affairs using a particular linguistic form. In contrast, later research on stance, primarily stemming from insights from the field of linguistic anthropology, sees stance, so the authors explain, as also located primarily in form but not as the product of an individual speaker but rather constructed in dialogue over consecutive turns and longer segments of conversation. Stance in this tradition is thus viewed as a dialogic and intersubjective construct, i.e. as a dialogue involving individuals' engagement with other subjectivities. Further approaches to stance in conversational analysis add a sequential and interactional view to this intersubjective view of stance, considering stance-taking within the practices of social interaction. Following this overview, Keisanen and Kärkkäinen advocate a further perspective on stance which focuses on complementing the study of language in stance-taking with an analysis of embodied actions (e.g. intonation, gazes, nods, body position, 
facial expressions) (cf. also O'Halloran, Tan and E, this volume on multimodal pragmatics). They illustrate this approach exemplarily by means of a multimodal analysis of an interaction in which bad news is relayed and received. The article closes by endorsing the need for a future synthesis of the approaches discussed to enhance our understanding of the pragmatic study of stance and to move to an understanding of stance not as tied to linguistic forms but rather as a product of ongoing activity, sequential position, language and the body.

Speech act sequences are addressed by César Félix-Brasdefer. In this article, he describes the foundations and beginnings of research on speech act sequences and also presents an overview of the structure and function of speech act sequences in a range of approaches to discourse in different social settings. Félix-Brasdefer begins the chapter by first examining the contribution of speech act theory to analyses of speech act sequences. Here he draws attention to the speaker-centered nature of speech act theory while at the same time pointing out that speech act theory paved the way for the analysis of speech act sequences with the introduction of concepts such as uptake, illocutionary force, conventionality, felicity conditions and indirectness, concepts which would later prove productive for analyses of speech act sequences. Attention then turns to the contribution made by anthropology (Hymes) and sociology (Goffman) to the study of speech act sequences, above all via concepts such as that of speech event (Hymes 1974) and interchange (Goffman 1971). In contrast to speech act theory, Félix-Brasdefer underlines, both of these approaches took the social context and also speaker-addressee negotiation of meaning into account and so motivated our understanding of the function and structure of speech act sequences. The author then examines how speech act sequences are conceptualised in a range of approaches to discourse focusing on social action and interaction (e.g. in linguistic approaches to discourse analysis, conversation analysis, interactional sociolinguistics, critical discourse analysis, computer-mediated discourse analysis, cross-cultural and interlanguage pragmatics), and across a range of discourse domains (e.g. classroom, media). In this context, he points out that depending on the approach to discourse, speech act sequences are referred to using a range of different terms, including macro-speech act, exchange, interactional move exchange, interchange, joint action, speech event, conversational sequences, macrosegments or entries. The chapter closes with a general call for an increase in empirical analyses of speech act sequences in a range of discourse settings and also for prosodic features and non-verbal actions to be incorporated in future analyses of speech act sequences.

Closely related to the study of speech act sequences is the study of phases in discourse, the latter understood as a series of sequences through which particular activities are realised. Phases in discourse is the topic of the chapter by Theodossia-Soula Pavlidou. Pavlidou begins her chapter by introducing the three major phases into which discourse is commonly split, namely the opening phase, the medial/core phase and the closing phase. She begins by providing a brief overview 
of a number of analyses of these three phases conducted by individual authors, such as Laver (1975) and Henne and Rehbock (1979), but then goes on to situate her discussion of phases, and of the different sub-phases of which these may be split, within the conversational analytic (CA) approach to discourse (cf. also Clift, this volume). This she does arguing the need to discuss both the internal structure of phases and also the transitions from one phase to another within the same theoretical framework. Moving on from this point, she then provides an overview of some of the tenets of conversation analysis, and focuses individually on the structure of the opening phase, the closing phase and the medial phase respectively and also transitions from one phase to the next. Each phase is shown to consist of a series of sequences, with the structure of the opening and closing phases more standard and routine than that of the medial phase. The overview of phase structure centres on the discourse of non-institutional landline telephone calls in the first instance, a discourse type which has played a key role in CA work. In addition, variation in the phase structure of each phase is examined as a function of cultural, technological and institutional variation, non-institutional land-line telephone calls being contrasted with mobile phone calls and institutional calls as well as with non-institutional land-line telephone calls carried out in different languages. The chapter closes with an illustrative analysis of the phases of a single phone call taken from the Corpus of Spoken Greek.

In contrast to the concentration of analyses of speech act sequences and indeed also of phase structure on spoken discourse, the concept of move structure is predominantly used in analyses of written texts within the context of genre analysis (cf. also Tardy and Swales, this volume). In her chapter focusing on move structure, Betty Samraj begins by adopting Swales' (2004: 228-229) definition of a move as a "discoursal or rhetorical unit that performs a coherent communicative function". The article then illustrates how this unit of analysis is employed to reveal the rhetorical structure of texts as used in social contexts and how it may explain how a particular text fulfils its overriding communicative purpose. Samraj continues by taking up the contentious question of move identification and also the question of how moves may be delineated from each other. She also considers issues pertinent to the linear and hierarchical ordering of moves and their constituent steps as well as the status of moves as obligatory or optional and highlights the importance of such issues for move structure analysis. After sketching the essential foci of move structure analysis, Samraj proceeds to look at the role of such macrostructural analysis with regard to questions of genre relatedness and variation particularly across disciplines or language, the latter focus introducing research in the area of contrastive rhetoric. The application of move structure analyses to pedagogical contexts is then taken up, with particular reference to applications in the contexts of English for Academic Purposes (EAP) and English for Research Purposes (ERP). Finally, an original analysis of moves in abstracts accompanying master's theses in three disciplines is presented which sheds light on some of the 
complexities of the analysis of global structure analysis discussed. The chapter concludes by highlighting a research desideratum above all in the area of comparative studies.

Silence as a discourse phenomenon is discussed by Michal Ephratt. In the introduction to her chapter, she makes an emphatic plea for an integrated and differentiated treatment of silence, criticising all work exclusively examining either verbal or non-verbal communication, and also all work presenting silence as a monolithic category. In Ephratt's view, paralanguage, including silence, should be dealt with as co-occurring with spoken language. Furthermore, different types and functions of silence need to be distinguished. The first part of her chapter provides a detailed survey of the research literature on silence divided into two sections. In the first section, an overview is given of approaches examining silence in the context of non-verbal communication. All researchers in this area have classified silence as a paralinguistic phenomenon, together with voice qualities and vocalisations, such as loudness and pitch, or laughter and sneezes, but the status of silence differs considerably across classifications. The second section reviews in greater detail literature dealing with silence as an object in its own right. Here the focus is on the different forms and functions of silence in communication. The author's critical comparison of studies and approaches shows radically diverging perspectives. While some scholars consider "socio-cultural silences" as, for instance, "the minute's silence to commemorate the dead" at public events, other scholars concern themselves only with such local silences as "gaps", "lapses" and "pauses" in everyday conversation. Several authors define silence relative to speech, or attempt to locate it in a more comprehensive context, emphasising the communicative functions of silence, conceptualising some types of silence as an equivalent or replacement of a speech act. At the beginning of the second part of her chapter, Ephratt underlines the heterogeneous nature of silence and the incompatibility of the various conceptualisations of silence emerging from the literature review. She considers it necessary to distinguish between communicative and non-communicative silences, and she is for situating communicative silences in the broader context of communication, and differentiating between different modes of speech as well as of silence. Against this background, the author postulates three basic types of silence, each conceptualised as a different type of communicative sign (in a semiotic sense) and located on a different level of communication (where a distinction is made between the paralinguistic, the linguistic and the extralinguistic level). Paralinguistic silence is classified as index. Certain types of unfilled pauses belong to this category. Linguistic silence (as Ephratt calls it), on the other hand, is classified as symbol. One example is silence when talk is expected, especially a particular type of talk. In this context, the author takes a closer look at types of linguistic silence serving the six functions specified in Jakobson's model of communication. The third basic type (on the extralinguistic level) is silence as an icon. Here the author suggests two subtypes, namely the unsaid and empty talk. Strategic silence 
in political discourse is mentioned as an example of the former subtype. The latter subtype of empty talk is characterised as disjoining noise and distinguished from small talk which serves Jakobson's phatic function of connecting people. The chapter ends with a model of silence in interaction summarising Ephratt's semiotic types of silence and their subtypes.

Jürgen Esser's chapter, entitled "Taxonomies of discourse types" opens part three of this volume, focusing on "Discourse types and domains". In his chapter, Esser provides a detailed survey of a range of taxonomies of discourse types, tracing their historical roots and especially discussing developments during the twentieth century and into the twenty-first century, with an outlook on potential future classifications. Initially, the author refers to the broad distinction between vulgar and elevated, i.e. everyday and literary, language made in ancient rhetoric and poetics, and also to the medieval controversy between "realism", assuming universal meanings of linguistic signs, and "nominalism", whose assumption of userbased meanings is immediately relevant to attempts at classifying discourse types. After briefly mentioning (realist) Saussure's notion of "parole" (Saussure 1916/1974), the author turns to the work of authors who can be considered forerunners of later taxonomic approaches. Here, (nominalist) Morris' definition of "discourse types" is quoted as well as the parameters he used for classifying them, which resulted in sixteen major types of discourse (Morris 1971). Further, Malinowski's emphasis on the context of situation is referred to (Malinowski 1923/1949), also Firth's classification of language functions, which seems to foreshadow speech act taxonomies (Firth 1957), and Skalička's elaboration of Saussurean "parole" (Skalička 1948). The main focus of this chapter is, however, on a range of classifications developed in the traditions of the Prague School and British contextualism and taxonomies of notional discourse types, and specifically on the various criteria on which these classifications are based. Taking Bühler's organon model and his three fundamental language functions as a starting point (Bühler 1934), the author first considers Jakobson's extended model of communication, in which six language functions correspond to the six constitutive factors of speech events which Jakobson had identified (Jakobson 1960). Then taxonomic approaches in functional stylistics are discussed, notably Havránek's notions of language functions, stylistic devices and functional dialects and their correlations (Havránek 1964), and Doležel's properties of text classes (e.g. Doležel 1968). Regarding typologies developed in the tradition of British contextualism, the discussion concentrates on the central concepts of register and genre, drawing on work by Gregory (e.g. 1967) and Halliday (e.g. 1978), and by Biber (e.g. 1989), Swales (1990) and Bhatia (2004) respectively. Finally, the author introduces four approaches which go beyond language functions and the communication situation and which take the cognitive dimension into consideration, resulting in notional classifications of discourse types. These four approaches are: (1) Werlich's text grammar, in which text types are correlated with cognitive processes (Werlich 
1976), (2) Longacre's criteria contingent succession, agent orientation and projection (Longacre 1983), (3) Virtanen's two-level taxonomy distinguishing between discourse types and text types which may realise discourse types (Virtanen 1992), and (4) van Dijk's concept of superstructures as recurrent abstract schemata of conventionalised text types (van Dijk 1980). At the end of his chapter, Esser provides a metatheoretical classification of all taxonomies discussed in a matrix which integrates the parameters and criteria on which these taxonomies are based. This matrix, the author argues, can be used to assess other taxonomies which have been or will be proposed.

Classroom discourse is the first domain dealt with in this part of the handbook. Shanru Yang and Steve Walsh present a very comprehensive overview, with particular emphasis paid to spoken communication in the second language classroom. The paper begins by sketching the institutional context of classroom discourse and considering the unique characteristics of discourse which result from this (teachers' control of patterns of communication, questioning, repair and modifying speech to learners). The authors then turn to the reasons for studying classroom discourse, namely the centrality of classroom discourse in both promoting and understanding learning processes, the need for teachers to understand classroom discourse in order to exploit and create opportunities for learning and finally, the need for a commonly accepted metalanguage of classroom discourse to promote understanding and communication. The main approaches which have been employed to study classroom discourse are then presented, namely interaction analysis, Sinclair and Coulthard's (1975) approach to discourse analysis and also conversation analysis (cf. Edmondson, this volume; Clift, this volume). Yang and Walsh describe how these approaches have been applied to the classroom context, highlighting their strengths and weaknesses. They then go on to propose a variable and dynamic approach to classroom discourse, an approach which, in contrast to other approaches, recognises the existence of many different classroom contexts, some more or less appropriate for particular pedagogic goals. The chapter closes with a discussion of future research directions. The authors point out in this context that the recent growth in popularity of content and language integrated learning (CLIL) poses a challenge for research in educational discourse, particularly with regard to the role of scaffolding, signalling switches between language-focused and content-focused discourse and also code-switching. Secondly, Yang and Walsh point out that the increasingly accepted insight that interaction with speakers of a range of backgrounds is a more adequate goal than appropriate individual productions has led to the concept of classroom interactional competence. This is proposed to offer future research potential to reveal interactional features which may impact positively on learning. Finally, the advent of corpus linguistic methods has changed and is changing research on classroom discourse (cf. Mahlberg, this volume). The authors advocate a combined conversation analytic/corpus linguistic approach for the analysis of classroom discourse. 
Medical discourse is the second domain dealt with in the present volume. In this contribution, Gillian Martin considers how pragmatics as a method of inquiry contributes to our knowledge and understanding of the complexities of communication in healthcare settings. Similar to the preceding chapter, Martin focuses primarily on spoken communication, and in particular on patient-healthcare provider interactions. The chapter first provides an overview of the methodological approaches which have been taken to medical discourse. A broad differentiation is made here between process analysis and microanalysis, the former involving, e.g. Interaction Process Analysis and the Roter Interaction Analysis System, the later encompassing studies of the institutional order in the tradition of critical discourse analysis and also studies focussing on the interaction order in the tradition of conversation analysis (cf. Bloor and Bloor, this volume; Clift, this volume). Following this, Martin addresses the place of pragmatics as a method of inquiry in medical discourse research, also pointing out the difficulties of defining clear boundaries between approaches. The article then turns to the domain of medical discourse itself, drawing in particular on pragmatic research. The primary structural and linguistic features are discussed along four main headings, namely asymmetry, routines, misalignment and indirectness/ directness. Here Martin highlights the gulf that frequently exists between the medical voice of the healthcare provider and the non-professional voice of patients, a gulf the result of differing assumptions and differing categories of interpretation due to differences in institutional, professional, lay and also national cultural identities. As such, patient-provider interactions within a single culture may be conceptualised as a form of intercultural communication with each party bringing a different set of sociopragmatic and pragmalinguistic expectations to interactions, such as with regard to who can utter which speech act in what context and at what stage in the discourse and also with regard to what way this speech act should be realised. Martin focuses initially on the single-culture context and then later examines medical discourse in the intercultural context, pointing out that the dangers of sociopragmatic and pragmalinguistic failure in intercultural contexts of patient-provider discourse are all the greater in such settings. The chapter closes with a discussion of future directions. Here Martin points out that previous research has focused predominantly on frontstage encounters between patients and providers. However, given a growing focus on treatment by multi-disciplinary teams, research on backstage encounters between providers themselves is of increasing importance. In addition, increased international mobility means that research in an intercultural and lingua franca context is growing in importance. Finally, the question as to the impact of new technologies and the resultant ease of access to medical information on patientprovider discourse remains ripe for research.

In Alison Johnson's chapter "Legal discourse: processes of making evidence in specialised legal corpora" the focus is on the domain of institutional legal discourse in general and on two types of institutional legal discourse in particular, 
namely police interviews and courtroom interaction, both discourse types involving institutional professionals such as police officers, lawyers and judges on the one hand, and lay participants such as suspects, defendants and witnesses on the other hand. In her analysis of these two discourse types, the author examines the practices employed to accept or deny verbal facts and the actions used to construct and negotiate evidence. These actions include such institutional activities as arguing, stance taking, doubting and rejecting. The author concentrates in particular on question design and the deployment of reported speech and quoting in legal contexts. Her investigations are based on large specialised corpora of recorded material from police interrogations and courtroom trials. At the beginning of her chapter, Johnson demonstrates how the words uttered in the courtroom by a defendant or a witness are not only legally relevant in the institutional context, but can be quoted and requoted, contextualised and recontextualised in the media and thus become also socially significant. She then characterises the two discourse types under inspection, i.e. police interviews and courtroom interaction, as complex genres with their specific rules, conventions and goals. After advocating forensic linguistics as a field of applied discourse analysis and providing an overview of the work done and the issues addressed in this field to date, the author turns to the pragmatics of questioning in legal institutions and outlines the interactional sociolinguistic approach she adopts in her corpus-based analysis. The findings of this analysis are presented in the second half of the chapter, which is focused on a detailed discussion of a range of specific patterns which include a form of the verb SAY identified in police interviews and in trials. In such contexts, these patterns are used strategically in making evidence, as shown in extensive samples of corpus material of these two types of legal discourse. In her conclusion, the author underlines that quoting is a key activity employed in institutional legal interaction by the professional participants as a means of appropriating the words of lay participants (who thus lose control over their own voice and identity). Quoting, in other words, transforms that which is personal into a professional, i.e. legal, entity, which may then, through the media, become public, for social and moral evaluation.

In her contribution on "Electronic Discourse", Miriam Locher concentrates especially on Web 2.0. ${ }^{3}$ Initially, the author considers the terminology which has been suggested for the object of study and also discusses the motivation of the various terms, which include "electronic discourse", "digital discourse", "e-communication" and "keyboard-to-screen communication". Locher opts for "computer-mediated communication" (CMC), which is still the best known and most widely used term in the field, despite the fact that today not only computers but also new media such as smartphones or tablets are used for this type of communication. Locher regards CMC as a specific subtype of electronic discourse. In the next section of her chapter, the author examines the dynamic development of CMC since the early 1990s, starting with email messages and information websites and arriving at a higher degree of participation and multimodality. This is essentially the develop- 
ment from Web 1.0 to Web 2.0, in which a range of new types of CMC has emerged, including chats, blogs, wikis, instant messaging, texting, virtual worlds and social network sites. The author emphasises the high speed with which such types appear or vanish and their uses, styles and practices change. Furthermore, she points out that the speed of this process, which is often increased by new technical options, makes it difficult to compare studies of CMC language and practices across relatively short periods of time. This discussion is followed by a literature review in which the author surveys linguistic research on CMC from the past two decades. In particular, she reviews several research strands which include the development of theoretical frameworks for the description of CMC language use and work on the distinctive features of particular CMC modes and genres such as emailing, listserv and interactive online games, to name only three. Other research has focused on pragmatic phenomena and interactive practices familiar from research into face-to-face offline communication. In the second half of her chapter, Locher provides an in-depth study of Facebook, based on her own recent research, for illustrating a number of multi-modal practices typical of communication in Web 2.0. Examples are microblogging (as in Facebook status updates), the use of messaging options and chat windows, and the uploading of pictures, photos and short videos. A special focus in this discussion is on acts of positioning and identity construction by employing the multimodal options offered in Facebook (cf. also O'Halloran, Tan and E, this volume).

The final chapter in this section on discourse types and domains focuses on press releases. Press releases represent a form of communication, written by organisations but drawn on and taken up by journalists. As such, they represent a discourse type situated at the interface of two discourse domains, that of media discourse and professional discourse. Their inclusion highlights the fuzzy boundaries between domains and also the analytical difficulties involved. Indeed, Geert Jacobs explains the fact that press releases have received limited attention in discourse studies to date with reference to their insular position occupied at this boundary. The chapter first addresses the position of press releases at the periphery of media discourse and professional discourse and the repercussions of this for their status as a genre. It then goes on to describe press releases as a type of projected discourse and highlights the role of preformulation, and the concepts of intertextuality and entextualisation, for this discourse type. Following this, three metapragmatic features of press releases are discussed, namely third-person self-reference, pseudo-quotation and the use of explicit semi-performatives, and their importance for an understanding of press releases is clearly illustrated. The final part of the paper is devoted to recent and future developments in research on press releases. The first concerns the influence of technological advances, in particular the internet and newly emerged methods of internet PR and online distribution, on the language of press releases. Jacobs draws our attention in this context to e-releases, a new hybridised discourse type which uses less preformulation and more personalised direct discourse. The 
second area of increasing interest concerns the way in which press releases are taken up by journalists in the media. Scholarship in this area investigates to what extent the texts of press releases find their way into the media. Research involves contrasting the texts of press releases with those of published newspaper texts but also increasingly adopting an ethnographic perspective to investigate how press releases are drawn on by journalists. Finally, Jacobs turns to multi-modality (cf. also O'Halloran, Tan and E, this volume) and highlights the need to extend the analysis of press releases to include a range of multi-modal interactions, such as online press conferences and video news releases.

\section{Perspectives}

The contributions to this volume reflect several emerging trends in discourse pragmatics. Firstly, corpora are playing an increasingly dominant role in discourse pragmatics (cf. Mahlberg, this volume). To date, work in discourse analysis has been predominantly qualitative (but cf., e.g., Johnson, this volume). However, with the availability of more, larger and different corpora and more sophisticated search tools, using corpora and corpus-linguistic methods will continue to increasingly complement qualitative work with quantitative studies (cf. also Jaworski and Coupland 1999: 36). Initially, corpora (in the specific corpus-linguistic sense of large machine-readable collections of language data) included written language exclusively (e.g. the Brown Corpus). Also, more recent corpora, while containing both written and spoken samples, were still heavily biased towards written language. The written part of the British National Corpus (BNC), for instance, a corpus totalling 100 million words, amounts to ninety per cent of the total corpus, the spoken part, accordingly, to only ten per cent. Corpora of spoken language alone, such as the Santa Barbara Corpus of Spoken American English (SBCSAE), tend to be relatively small (in this case 249,000 words). Furthermore, if spoken language is included in a corpus, it is usually included in a transcribed, i.e. written, version, with notational conventions only insufficiently making up for the loss of prosodic and paralinguistic etc. features. The SBCSAE is, in fact, a rare exception in this regard as it comprises the sound files along with the transcripts of the recorded material. Encouragingly, the British component of the International Corpus of English (ICE) has very recently followed the lead of the SBCSAE and released 300 audio recordings of the corpus which may be played aligned with the relevant transcriptions. Further releases of transcripts linked to audio files would make corpora more accessible for pragmatic analyses. Another exceptional feature of the SBCSAE concerns the fact that it provides systematically detailed demographic data on all speakers recorded, including not only age and sex, but also where speakers were born, where they live and what their occupation is, etc. It would be desirable if detailed information of this kind was available in all corpora, since this is a prerequi- 
site for correlating language patterns and pragmatic phenomena in discourse with the socio-cultural characteristics of the participants.

A further desideratum concerns the subdivisions made in corpora beyond the basic distinction between spoken and written language. Examples from the Corpus of Contemporary American English (COCA) include "ACADEMIC", "FICTION", "MAGAZINE" and "NEWSPAPER", with subcategories such as "Education", "History" and "Medicine", which refer to domains rather than to discourse type or genre. While attempts have been made to use more elaborate classification systems (e.g. in the BNC), the categories generally used in corpora appear to be, by and large, relatively broad, intuitive and not very consistent; as a rule, they are not clearly defined and not easily comparable across corpora. Yet, systematic classifications and subcategorisations are needed to make better and more differentiated use of corpora in investigating the pragmatics of discourse types and genres and in establishing specific patterns and practices (cf. Lee 2008: 95; Esser, this volume; Tardy and Swales, this volume).

Finally, what is lacking for a more fruitful and efficient use of corpora in discourse studies is an annotation system for discourse tagging. While many corpora are tagged for grammatical features, only few corpora are tagged for pragmatic features (cf., e.g. Weisser forthcoming; cf. also McEnery, Xiao and Tono 2006: 34; 40-41), a fact which makes form-based searches the rule. Consequently, analysts face the difficulties of precision and recall (cf., Jucker 2009), precision referring to the predicament that searches generate many more concordances than those of interest to the researcher; recall referring to the difficulty that many speech act realisations, such as, for example, less formulaic speech acts, are irretrievable. One of the rare exceptions to this general lack of functional annotation in larger corpora is SPICE-Ireland, based on the spoken part of ICE-Ireland, i.e. the Irish component of the International Corpus of English (ICE) (cf. Weisser forthcoming for a more comprehensive overview). SPICE-Ireland is annotated for pragmatic features such as, for instance, discourse markers and illocutionary types as well as partly for prosodic information (cf. Kallen and Kirk 2012; Kirk 2013). Many more corpora of this kind are needed and much more work is required on systems for the pragmatic annotation of discourse in order to overcome the restrictions of form-based searches of pragmatic phenomena in corpora and make function-based searches possible.

Considering the growing interest in multimodality (highlighted in the present volume not only by O'Halloran, Tan and E, but also in other contributions, e.g. by Keisanen and Kärkkäinen, and Jacobs; cf. also Bhatia, Flowerdew and Jones 2008: 9-10), what is needed are not only more and larger corpora of written and particularly spoken language, but also multimodal corpora. Hence, what is required to facilitate multimodal discourse analysis and specifically multimodal pragmatics are corpora comprising transcripts and audio files as well as video files. Given today's general standards of computer technology available not only to professionals and 
researchers but also to students, the technical prerequisites of compiling such corpora should be relatively unproblematic although, as Lee (2008: 96) points out, collection, storage and analysis will be more complex and corpora will necessarily be smaller in size relative to current mega-corpora.

Multimodality is also a key topic in the analysis of electronic discourse or computer-mediated communication (CMC) (cf. Locher, this volume, also for a discussion of terminology). The pragmatics of CMC in general represents a burgeoning and thriving field (cf. Herring, Stein and Virtanen 2013). Among the many fascinating aspects meriting research in this area is the on-going and rapid change in language use and interactional practices, involving the birth, development and sometimes death of a fairly large number of discourse types and genres and also ways of communicating. Since the advent of Web 2.0, multimodality is playing an increasingly important role in CMC and the new media as a variety of multimodal features and resources are integrated into social networking sites, such as Facebook, or virtual worlds, such as Second Life.

Another major trend in the study of discourse pragmatics is the increasing influence of critical discourse analysis (CDA). Apart from the article specifically dealing with this approach in the current handbook (Bloor and Bloor, this volume), further articles emphasise the shared interests and commitments of CDA and other approaches to discourse (cf. Simon-Vandenbergen, this volume; Mahlberg, this volume; Tardy and Swales, this volume). This trend points to a growing desire among some researchers in discourse studies to make their work immediately relevant also outside of academia and to directly contribute to the solution of social problems in society by uncovering and exposing power relations, ideologies and manipulation (cf. also, e.g., Wodak 2011).

All innovations and new trends should not blind us to the fact that there is still a lot of work to be done in more traditional areas within the paradigm of discourse pragmatics, areas which could be referred to as "normal science", to use Thomas Kuhn's term (Kuhn 1962). For instance, as van Dijk (2006: xvii) notes, “dozens of genres have been systematically analysed for their overall organisation, their moves, style, lexicon and social functions, but there are many hundreds if not thousands of genres, in many different cultures, still waiting for such systematic description", and indeed even in such well-researched languages as English there are still doubtlessly countless genres awaiting analysis. Moreover, such detailed descriptions of individual genres can be used and are used in a number of applied contexts. Descriptions of a range of discourse types continue to be used, for instance, in (foreign) language teaching and communication training, and indeed on a general level, education constitutes an important field of application for discourse studies, as demonstrated by Yang and Walsh, Edmondson, and Simon-Vandenbergen (all this volume). However, such discourse type descriptions also have applications outside of the educational arena contrary to what is sometimes suggested by those focusing more on the social and psychological side of discourse 
(cf., e.g. Coupland 2000: 5). Indeed, descriptions of discourse types may serve as models in other areas of application such as computer studies and research into artificial intelligence provided the relevant genre conventions have been analysed with sufficient delicacy. An early example of this type of application is the attempt to use a book-length treatment of phatic discourse (Schneider 1988) as a starting point for developing a computational model of small talk as a component of the "communicative competence" of so-called relational agents, i.e. artificially intelligent avatars on computers interacting with human users (cf., e.g., Bickmore 1999 and 2003; also Bickmore and Cassell 2005). This project, originally carried out at the Massachusetts Institute of Technology (MIT), has shown the potential, but also the difficulties of this kind of application. For instance, it became clear that very detailed descriptions of linguistic and interactive patterns derived from larger data bases were needed, as well as generalisations about these. Such research continues to represent a research desideratum.

Returning to van Dijk's remark (2006: xvii) about the numerous genres in many different cultures still awaiting systematic description, it is worth noting that research comparing genres across cultures also represents a research gap. Early work in "contrastive rhetoric" was speculative rather than descriptive. Even though Kaplan (1966) based his famous study on a relatively large collection of student essays, he was not really interested in this particular genre. He merely used these essays, which had been written in non-native English by students from various language backgrounds at American universities, to postulate abstract "cultural thought patterns". In the late 1970s and 1980s, contrastive discourse analysis developed as an extension of the levels of analysis in the then still popular original version of contrastive linguistics (cf., e.g., Sajavaara and Lehtonen 1980). In the 1990s, some contrastive work emerged in the context of language for specific purposes (LSP) and specifically English for academic purposes (EAP), employing the framework of Swalesian genre analysis (cf. Tardy and Swales, this volume), known as contrastive genre analysis. A typical example is Oldenburg (1992) comparing the closing sections of research articles written in English and German. The twenty-first century has seen a renewed interest in contrastive linguistics and a new wave of empirical studies. These are, as a rule, corpus-based and use corpus-linguistic methods. While often the focus is on contrastive grammar, there is also some work in contrastive discourse analysis (cf., e.g., Taboada, Doval Suárez and González Álvarez 2013, in which, among other phenomena, some pragmatic features are compared across a number of European languages). An example of a large-scale in-depth study in this area of contrastive analysis is Barron (2012), a book-length comparison of the genre (and subgenres) of public information messages in Ireland and Germany (e.g. of anti-smoking campaigns). This comparison involves both written and spoken language, in print, audio and visual media. Indeed, considering the range of features examined, topics covered and the relation to social context, this type of study goes well beyond a purely linguistic compari- 
son and may be more aptly characterised cross-cultural (rather than merely contrastive) genre analysis.

Contrastive and cross-cultural discourse analysis is concerned with contrasting genres across languages. Such analyses are, in other words, inter-lingual. Discourse variation does, however, also occur within languages, so to speak, i.e. across (native speaker) varieties of the same language. Yet, this is a largely under-researched area, as is more generally the area of intra-lingual pragmatic variation, not just in macropragmatics, but also in micropragmatics. In recent years, this research gap has been addressed in variational pragmatics, a field of research at the interface of pragmatics with dialectology and sociolinguistics (cf., e.g., Schneider and Barron 2008; Barron and Schneider 2009; Schneider 2010; Barron in press, forthcoming). However, of the five levels of pragmatic analysis distinguished in the framework of variational pragmatics, only two have received substantial attention. These are the formal and the actional levels, i.e. the levels on which respectively discourse markers and speech acts are examined (cf., e.g., a recent volume by Aijmer 2013 on discourse markers). Studies on levels above the speech act, on which interactional sequences, topic management and discourse organisation can be investigated, remain scarce (cf. Schneider 2012 for a summary). One of the few macropragmatic studies in variational pragmatics is Schneider (2008), comparing small talk in the English, Irish and U.S.-American varieties of English. These levels remain ripe for further research. Similarly, a broadening of the current focus of variational pragmatic research on regional variation, and particularly on national variation, to include macro-social factors, such as ethnic identity, age, gender and socio-economic class, represents a desideratum.

\section{Conclusion}

In conclusion then, this handbook represents an attempt to bring together some of the central approaches to discourse pragmatics and to highlight recent, current and future developments in the field. As has become apparent above, the various approaches to discourse are in continual flux. The influence of external developments, such as the recent technological developments, is one force of change responsible, for instance, for the advent of corpus-linguistic approaches to the study of discourse and also for the development of multi-modal pragmatics. On another level, such external developments introduce new genres and communication patterns which themselves challenge established approaches and trigger developments within these in turn. Other developments in discourse pragmatics may involve the emergence of new approaches from traditional approaches. We need only think in this regard of the emergence of mediated discourse analysis from CDA. Similarly, it has to be recognised that no approach exists in a vacuum but is rather continually influencing and being influenced and impacted on in a process of cross-fertilisation. 
The advent of critical genre analysis, the social commitment of discourse analysis in SFL to resolving social inequalities and also the emergence of corpus-based critical discourse analysis underlines this trend. The current handbook encourages readers to embrace the many approaches within discourse pragmatics to continue this cross-fertilisation of ideas.

\section{Notes}

1. The differences between Saussure's concepts "langue" and "parole" on the one hand and Chomsky's concepts "competence" and "performance" are not relevant in the present context.

2. Edmondson's contribution was among the first chapters commissioned for this handbook. It turned out to be the final paper which he completed. Willis J. Edmondson died in December 2009. The editors of this volume, both of whom had the pleasure to work with Willis Edmondson, are grateful to Juliane House for revising this chapter, in which the features typical of Edmondson's sharp wit and critical intellect have been retained.

3. Web 1.0 is extensively covered in volume 9 of this handbook series on the "Pragmatics of Computer-Mediated Communication" (2013), edited by Herring, Stein and Virtanen. Locher (this volume) includes a brief overview of the areas covered in that volume.

\section{References}

Aijmer, Karin

2013 Understanding Pragmatic Markers: A Variational Pragmatic Approach. Edinburgh: Edinburgh University Press.

Andersen, Gisle and Karin Aijmer (eds.)

2011 Pragmatics of Society. Berlin/Boston: De Gruyter Mouton. Austin, John L.

1962 How to Do Things with Words. Cambridge, MA: Harvard University Press. Barron, Anne

2012 Public Information Messages: A Contrastive Genre Analysis of State-Citizen Communication. Amsterdam/Philadelphia: Benjamins.

Barron, Anne

in press Variational pragmatics. In: Carol A. Chapelle (ed.), The Encyclopedia of Applied Linguistics (EAL), Oxford: Wiley-Blackwell. Online. Retrieved on November 15, 2013 from www.encyclopediaofappliedlinguistics.com.

Barron, Anne

forthcoming Variational pragmatics. In: Anne Barron, Gerard Steen and Yueguo Gu (eds.), Routledge Handbook of Pragmatics. London/New York: Routledge.

Barron, Anne and Klaus P. Schneider

2009 Variational pragmatics: Studying the impact of social factors on language use in interaction. Intercultural Pragmatics 6(4): 425-442. 
Bhatia, Vijay

2004 Worlds of Written Discourse: A Genre-Based View. London: Continuum.

Bhatia, Vijay K., John Flowerdew and Rodney H. Jones (eds.)

2008 Advances in Discourse Studies. London/New York: Routledge.

Bhatia, Vijay K., John Flowerdew and Rodney H. Jones

2008 Approaches to discourse analysis. In: Vijay K. Bhatia, John Flowerdew and Rodney H. Jones (eds.), Advances in Discourse Studies, 1-17. New York: Routledge.

Biber, Douglas

1989 A typology of English texts. Linguistics 27: 3-43.

Bickmore, Timothy

1999 A computational model of small talk. (Discourse and Dialogue for Interactive Systems, MAS 962.) Retrieved on November 13, 2013 from http://web.media. mit.edu/ bickmore/Mas962b/.

Bickmore, Timothy

2003 Relational agents: Effecting change through human-computer realationships. $\mathrm{Ph}$. D. thesis, Massachusetts Institute of Technology. Retrieved on 6 December 2013, from http://affect.media.mit.edu/pdfs/03.bickmore-phd.pdf

Bickmore, Timothy and Justine Cassell

2005 Social dialogue with embodied conversational agents. In: Jan van Kuppevelt, Laila Dybkjaer and Niels Ole Bernsen (eds.), Advances in Natural Multimodal Dialogue Systems, 23-54. Dordrecht: Springer.

Blas Arroyo, José Luis

2010 Interpersonal issues in political discourse. In: Miriam Locher and Sage L. Graham (eds.), Interpersonal Pragmatics, 405-434. Berlin/New York: De Gruyter Mouton.

Brown, Penelope and Stephen C. Levinson

1978 Universals in language usage: Politeness phenomena. In: Esther N. Goody (ed.), Questions and Politeness: Strategies in Social Interaction, 56-289. Cambridge: Cambridge University Press.

Brown, Penelope and Stephen C. Levinson

1987 Politeness: Some Universals in Language Usage. Cambridge/New York: Cambridge University Press.

Bublitz, Wolfram and Neal R. Norrick (eds.)

2011 Foundations of Pragmatics. Berlin/Boston: De Gruyter Mouton.

Bühler, Karl

1934 Sprachtheorie: Die Darstellungsfunktion der Sprache. Jena: Fischer Verlag.

Cap, Piotr

2011 Micropragmatics and macropragmatics. In: Wolfram Bublitz and Neal R. Norrick (eds.), Foundations of Pragmatics, 51-75. Berlin/Boston: De Gruyter Mouton.

Chilton, Paul

2004 Analysing Political Discourse: Theory and Practice. London/New York: Routledge.

Chomsky, Noam

1965 Aspects of the Theory of Syntax. Cambridge, MA: MIT Press. 
Coupland, Justine

2000 Introduction: Sociolinguistic perspectives on small talk. In: Justine Coupland (ed.), Small Talk, 1-25. Harlow: Longman.

Culpeper, Jonathan

2011 Politeness and impoliteness. In: Gisle Andersen and Karin Aijmer (eds.), Pragmatics of Society, 393-438. Berlin/Boston: De Gruyter Mouton.

Doležel, Lubomír

1968 Russian and Prague School functional stylistics. Style 2: 143-158.

Eggins, Suzanne and Diana Slade

1997 Analyzing Casual Conversation. London/New York: Cassell.

Fairclough, Norman

2003 Analysing Discourse: Textual Analysis for Social Research. London: Routledge.

Firth, John R.

1957 The technique of semantics. In: John R. Firth (ed.), Papers in Linguistics 1934-1951, 7-33. London: Oxford University Press.

Flanders, Ned A.

1970 Analyzing Teaching Behavior. Reading, MA: Addison-Wesley.

Flowerdew, John

2013 Discourse in English Language Education. London/New York: Routledge.

Forceville, Charles J. and Eduardo Urios-Aparisi (eds.)

2009 Multimodal Metaphor. Berlin/New York: De Gruyter Mouton.

Gee, James P. and Michael Handford (eds.)

2012 The Routledge Handbook of Discourse Analysis. London: Routledge.

Goffman, Erving

1971 Relations in Public: Microstudies of the Public Order. Harmondsworth, UK: Penguin Books.

Gregory, Michael

1967 Aspects of varieties differentiation. Journal of Linguistics 3: 177-198.

Halliday, Michael A. K.

1978 Language as Social Semiotic: The Social Interpretation of Language and Meaning. London: Edward Arnold.

Halliday. Michael A. K. and Christian M. I. M. Matthiessen

2004 An Introduction to Functional Grammar. London: Arnold.

Havránek, Bohuslav

1964 The functional differentiation of the standard language. In: Paul L. Garvin (ed. and transl.), A Prague School Reader on Esthetics, Literary Structure, and Style, 3-16. Washington, D.C.: Georgetown University Press.

Henne, Helmut and Helmut Rehbock

1979 Einführung in die Gesprächsanalyse. Berlin: Walter de Gruyter.

Herring, Susan, Dieter Stein and Tuija Virtanen

2013 Pragmatics of Computer-Mediated Communication. Berlin/Boston: De Gruyter Mouton.

Hyland, Ken and Brian Paltridge

2013 Bloomsbury Companion to Discourse Analysis. London/New York: Bloomsbury Academic. 
Hymes, Dell

1974 Foundations in Sociolinguistics: An Ethnographic Approach. Philadelphia: University of Pennsylvania Press.

Jakobson, Roman

1960 Closing statement: Linguistics and poetics. In: Thomas A. Sebeok (ed.), Style in Language, 350-377. Cambridge, MA: MIT Press.

Jaworski, Adam and Nikolas Coupland (eds.)

1999 The Discourse Reader. London: Routledge.

Johnstone, Barbara

2008 Discourse Analysis. Second edition. Malden, MA: Blackwell.

Jucker, Andreas H.

2009 Speech act research between armchair, field and laboratory: The case of compliments. Journal of Pragmatics 41(8): 1611-1635.

Jucker, Andreas H. and Irma Taavitsainen (eds.)

2010 Historical Pragmatics. Berlin/New York: De Gruyter Mouton.

Jucker, Andreas H. and Irma Taavitsainen

2012 Pragmatic variables. In: Juan Manuel Hernández-Campoy and Juan Camilo Conde-Silvestre (eds.), The Handbook of Historical Sociolinguistics, 293-306. Oxford: Blackwell.

Kallen, Jeffrey L. and John M. Kirk

2012 SPICE-Ireland: A User's Guide; Documentation to Accompany the SPICEIreland Corpus: Systems of Pragmatic Annotation in ICE-Ireland. Belfast: Cló Ollscoil na Banríona.

Kaplan, Robert B.

1966 Cultural thought patterns in intercultural education. Language Learning 16: $1-20$.

Kirk, John M.

2013 Beyond the structural levels of language: An introduction to the SPICE-Ireland corpus and its uses. In: Janet Cruikshank and Robert McColl Millar (eds.), After the Storm, 207-232. Aberdeen: Forum for Research on the Languages of Scotland and Ireland.

Kuhn, Thomas S.

1962 The Structure of Scientific Revolutions. Chicago: University of Chicago Press.

Lakoff, George

1987 Women, Fire, and Dangerous Things. Chicago/London: University of Chicago Press.

Laver, John

1975 Communicative functions of phatic communion. In: Adam Kendon, Richard M. Harris and Mary Ritchie Key (eds.), The Organization of Behavior in Faceto-Face Interaction, 215-238. The Hague: Mouton.

Lee, David Y.W.

2008 Corpora and discourse analysis: New ways of doing old things. In: Vijay K.

Bhatia, John Flowerdew and Rodney H. Jones (eds.), Advances in Discourse Studies, 86-99. New York: Routledge.

Locher, Miriam A. and Sage L. Graham (eds.)

2010 Interpersonal Pragmatics. Berlin/New York: De Gruyter Mouton. 
Longacre, Robert E.

1983 The Grammar of Discourse. New York: Plenum.

Malinowski, Bronislaw

[1923] 1949 The problem of meaning in primitive languages. Supplement I to Charles

K. Ogden and Ivor A. Richards, The Meaning of Meaning, Tenth edition, 296-336. London: Routledge \& Kegan Paul.

Martin, James R. and David Rose

2007 Working with Discourse: Meaning beyond the Clause. London: Continuum.

Martin, James R. and Peter R. R. White

2005 The Language of Evaluation: Appraisal in English. Basingstoke/New York: Palgrave Macmillan.

McEnery, Tony, Richard Xiao and Yukio Tono

2006 Corpus-Based Language Studies: An Advanced Resource Book. London/New York: Routledge.

Morris, Charles

1971 Writings on the General Theory of Signs. The Hague/Paris: Mouton.

Nevala, Minna

2010 Politeness. In: Andreas H. Jucker and Irma Taavitsainen (eds.), Historical Pragmatics, 419-450. Berlin/New York: De Gruyter Mouton.

Oldenburg, Hermann

1992 Angewandte Fachtextlinguistik: "Conclusions” und Zusammenfassungen. Tübingen: Narr.

Sajavaara, Kari and Jaako Lehtonen (eds.)

1980 Papers in Discourse and Contrastive Discourse Analysis. Jyväskylä: University of Jyväskylä, Department of English.

Saussure, Ferdinand de

[1916] 1974 Cours de Linguistique Générale, publié par Charles Bally et Albert Sèchehaye avec la collaboration de Albert Riedlinger, édition critique péparé par Tullio Mauro. Paris: Payot.

Sbisà, Marina and Ken Turner

2013 Pragmatics of Speech Actions. Berlin/Boston: De Gruyter Mouton.

Schiffrin, Deborah, Deborah Tannen and Heidi E. Hamilton (eds.)

2003 The Handbook of Discourse Analysis. Malden, MA: Blackwell.

Schmid, Hans-Jörg (ed.)

2012 Cognitive Pragmatics. Berlin/Boston: De Gruyter Mouton.

Schneider, Klaus P.

1988 Small Talk: Analysing Phatic Discourse. Marburg: Hitzeroth.

Schneider, Klaus P.

2003 Diminutives in English. Tübingen: Niemeyer.

Schneider, Klaus P.

2008 Small talk in England, Ireland, and the USA. In: Klaus P. Schneider and Anne Barron (eds.), Variational Pragmatics: A Focus on Regional Varieties in Pluricentric Languages, 99-139. (Pragmatics \& Beyond New Series, Vol. 178.) Amsterdam/Philadelphia: Benjamins.

Schneider, Klaus P.

2010 Variational pragmatics. In: Mirjam Fried, Jan-Ola Östman and Jef Verschueren (eds.), Variation and Change: Pragmatic Perspectives, 239-267. Amsterdam/ Philadelphia: Benjamins. 
Schneider, Klaus P.

2012 Pragmatics. In: Raymond Hickey (ed.), Areal Features of the Anglophone World, 463-486. Berlin/Boston: De Gruyter Mouton.

Schneider, Klaus P. and Anne Barron (eds.)

2008 Variational Pragmatics: A Focus on Regional Varieties in Pluricentric Languages (Pragmatics \& Beyond New Series, Vol. 178.) Amsterdam/Philadelphia: Benjamins.

Schneider, Klaus P. and Anne Barron

2008 Where pragmatics and dialectology meet: Introducing variational pragmatics. In: Klaus P. Schneider and Anne Barron (eds.), Variational Pragmatics: A Focus on Regional Varieties in Pluricentric Languages (Pragmatics \& Beyond New Series, Vol. 178.), 1-32. Amsterdam/Philadelphia: Benjamins.

Schnurr, Stephanie

2010 Humour. In: Miriam Locher and Sage L. Graham (eds.), Interpersonal Pragmatics, 307-326. Berlin/New York: De Gruyter Mouton.

Scollon, Ron

2001 Mediated Discourse: The Nexus of Practice. London/New York: Routledge.

Searle, John

1969 Speech Acts: An Essay in the Philosophy of Language. Cambridge: Cambridge University Press.

Sinclair, John M. and Malcolm Coulthard

1975 Toward an Analysis of Discourse: The English Used by Teachers and Pupils. London: Oxford University Press.

Skalička, Vladimír

1948 The need for a linguistics of 'la parole'. Recueil linguistique de Bratislava 1: $21-38$.

Stewart, Dugald (ed.)

1822 The Works of Thomas Reid; with an Account of His Life and Writings. Vol. I-III. New York: Evert Duyckinck, Collins and Hannay, and R. and W.A. Bartow.

Swales, John M.

1990 Genre Analysis: English in Academic and Research Settings. Cambridge: Cambridge University Press.

Swales, John M.

2004 Research Genres: Explorations and Applications. Cambridge: Cambridge University Press.

Taboada, Maite, Susana M. Doval-Suárez and Elsa M. González Álvarez (eds.)

2013 Contrastive Discourse Analysis: Functional and Corpus Perspectives. Sheffield: Equinox.

Titscher, Stefan, Michael Meyer, Ruth Wodak and Eva Vetter (eds.)

2000 Methods of Text and Discourse Analysis. London: Sage. van Dijk, Teun A.

1980 Textwissenschaft: Eine interdisziplinäre Einführung. München: Deutscher Taschenbuch Verlag.

van Dijk, Teun A.

2006 Discourse Studies: A Multidisciplinary Introduction. $2^{\text {nd }}$ edition. London: Sage. 
Vine, Bernadette

2010 Interpersonal issues in the workplace. In: Miriam Locher and Sage L. Graham (eds.), Interpersonal Pragmatics, 329-351. Berlin/New York: De Gruyter Mouton.

Virtanen, Tuija

1992 Issues of text typology: Narrative - a 'basic' type of text? Text 12: 293-310.

Weisser, Martin

forthcoming Corpora. In: Anne Barron, Gerard Steen and Yueguo Gu (eds.), Routledge Handbook of Pragmatics. London/New York: Routledge.

Werlich, Egon

1976 A Text Grammar of English. Heidelberg: Quelle und Meyer.

Widdowson, Henry G.

2004 Text, Context, Pretext: Critical Issues in Discourse Analysis. Oxford: Blackwell.

Wodak, Ruth

2011 Critical discourse analysis: Overview, challenges, and perspectives. In: Gisle Andersen and Karin Aijmer (eds.), Pragmatics of Society, 627-650. Berlin/ Boston: De Gruyter Mouton.

Zienkowski, Jan, Jan-Ola Östman and Jef Verschueren (eds.)

2011 Discursive Pragmatics. Amsterdam/Philadelphia: Benjamins.

\section{Corpora}

British National Corpus. Retrieved on November 13, 2013 from http://www.natcorp.ox.ac. uk/.

Brown Corpus. Retrieved on November 13, 2013 from http://icame.uib.no/brown/bcm.html.

Corpus of Contemporary American English. Retrieved on November 13, 2013 from http:// corpus.byu.edu/coca/.

Corpus of Spoken Greek, Institute of Modern Greek Studies (M. Triandafyllidis Foundation), Aristotle University of Thessaloniki. Retrieved on October 21, 2013 from http://www.ins.web.auth.gr/index.php?option=com_content\&view=article \& $\mathrm{id}=506 \&$ Itemid $=165 \&$ lang $=$ en .

International Corpus of English. Retrieved on November 13, 2013 from http://ice-corpora. net/ice/.

International Corpus of English: British component (ICE-GB). Retrieved on November 13, 2013 from http://www.ucl.ac.uk/english-usage/projects/ice-gb/.

Santa Barbara Corpus of Spoken American English. Retrieved on November 13, 2013 from http://www.linguistics.ucsb.edu/research/santa-barbara-corpus.

SPICE-Ireland. Retrieved on November 13, 2013 from http://www.qub.ac.uk/sites/ICEIreland/ICE-Ireland/ICE-IrelandCD-ROMs/. 
Brought to you by | Leuphana Universität Lüneburg

Authenticated

Download Date | 2/18/20 10:56 AM 